\title{
UM ENCONTRO COM A DIVERSIDADE NA EDUCAÇÃO INFANTIL POR MEIO DO PROJETO "SIMPLESMENTE DIFERENTE" SOB A PERSPECTIVA DO PROFESSOR, DA CRIANÇA E DA FAMÍLIA
}

\author{
UM ENCUENTRO CON LA DIVERSIDADE EN LA EDUCACIÓN INFANTIL A \\ TRAVÉS DEL PROYECTO “SIMPLEMENTE DIFERENTE” EN LA PERSPECTIVA \\ DEL PROFESOR, DEL NIÑO Y DE LA FAMILIA
}

\author{
A MEETING WITH DIVERSITY IN ELEMENTARY SCHOOL EDUCATION \\ THROUGH THE PROJECT "SIMPLESMENTE DIFERENTE" FROM THE \\ PERSPECTIVE OF THE TEACHER, THE CHILD AND THE FAMILY
}

\author{
Luciana Aparecida de ARAUJO ${ }^{1}$ \\ Ana Paula CORDEIRO ${ }^{2}$ \\ Claudia Regina Mosca GIROTO ${ }^{3}$
}

\begin{abstract}
RESUMO: Sob a perspectiva da educação inclusiva, a Educação Infantil deve atender às especificidades da diversidade de alunos, incluindo o público-alvo da Educação Especial. Frente a tal compromisso, este estudo objetivou investigar as concepções sobre diversidade junto às crianças de uma classe de Educação Infantil II, familiares e professora, a partir do projeto "Simplesmente Diferente", elaborado e desenvolvido colaborativamente por meio de projeto de trabalho. A análise compreendeu eixos temáticos, dentre os quais destacamos "Concepções sobre diversidade no contexto da Educação Infantil na perspectiva inclusiva", que indiciou possibilidades de ressignificação sobre diversidade, a partir da metodologia utilizada, bem como a necessidade de a escola pautar esse tema em suas práticas pedagógicas.
\end{abstract}

PALAVRAS-CHAVE: Diversidade. Educação Infantil. Educação Inclusiva. Educação Especial.

RESUMEN: A partir de la perspectiva de la educación inclusiva, la Educación Infantil debe atender a las especificidades de la diversidad de sus alumnos, incluyendo el público objetivo

\footnotetext{
${ }^{1}$ Universidade Estadual Paulista (UNESP), Marília - SP - Brasil. Docente do Programa de Pós-Graduação em Educação (PPGE) e do Departamento de Didática, Faculdade de Filosofia e Ciências (FFC). Doutora em Educação. ORCID: <https://orcid.org/0000-0003-1147-5039>. E-mail: luciana.penitente @ unesp.br

2 Universidade Estadual Paulista (UNESP), Marília - SP - Brasil. Docente do Mestrado Profissional de Sociologia em Rede Nacional (PROFSOCIO) e do Departamento de Didática, Faculdade de Filosofia e Ciências (FFC). Doutora em Educação. E-mail: a.cordeiro@unesp.br

${ }^{3}$ Universidade Estadual Paulista (UNESP), Marília - SP - Brasil. Docente do Programa de Pós-Graduação em Educação (PPGE) e do Departamento de Educação Especial, Faculdade de Filosofia e Ciências (FFC). Docente do Programa de Pós-Graduação em Educação Escolar (PPGEE), Faculdade de Ciências e Letras (FCLAr), Campus de Araraquara/SP. Doutora em Educação. ORCID: 〈https://orcid.org/0000-0001-6267-8085>. E-mail: claudia.mosca@unesp.br
} 
de la Educación Especial. Frente a tal compromiso, este estudio objetivó investigar las concepciones sobre diversidad junto a los niños de una clase de Educación Infantil II, familiares y profesora, a partir del proyecto "Simplemente Diferente", elaborado y desarrollado colaborativamente por medio de proyecto de trabajo. El análisis abarcó ejes temáticos, entre los cuales destacamos "Concepciones sobre diversidad en el contexto de la Educación Infantil en la perspectiva inclusiva", que indició posibilidades de resignificación sobre diversidad, a partir de la metodología utilizada, así como la necesidad de que la escuela pautar ese tema en sus respectivas prácticas pedagógicas.

PALABRAS CLAVE: Diversidad. Educación Infantil. Educación Inclusiva. Educación Especial.

ABSTRACT: From the perspective of inclusive education, Childhood Education must meet the specificities of the diversity of students, including the target audience of Special Education. Facing such commitment, this study aimed to investigate the conceptions about diversity among the children of a kindergarten class, their families and teacher, from the project "Simplesmente Diferente", elaborated and developed collaboratively through a work project. The analysis included thematic axes, among which we highlighted "Conceptions about diversity in the context of the Childhood Education in the inclusive perspective", which indicated possibilities of re-signification on diversity, based on the methodology used, as well as the necessity for the school to set this topic in its pedagogical practices.

KEYWORDS: Diversity. Childhood education. Inclusive education. Special education.

\section{Introdução}

A inclusão escolar tem sido tema atualmente debatido por pesquisadores e profissionais da área da educação, a partir da perspectiva de educação inclusiva que vai além da inserção do aluno no ensino regular, que assegure não apenas o acolhimento de todos, mas garanta ensino de qualidade e permanência nos diferentes âmbitos do contexto educacional, com vistas à formação do cidadão crítico para a vida autônoma em sociedade (BRASIL, 2008).

Desde a promulgação da Política Nacional de Educação Especial na Perspectiva da Educação Inclusiva (PNEEPEI) (BRASIL, 2008), a Educação Infantil teve reforçado o compromisso de atender às especificidades da diversidade de alunos matriculados nessa modalidade educacional, o que inclui os alunos que constituem o público-alvo da Educação Especial: alunos com deficiências; transtornos globais do desenvolvimento (TGDs) ou altas habilidades/superdotação.

Nesse sentido, a Educação Infantil passou a se comprometer, mais pontualmente, com o respeito às diferenças e, consequentemente, com o caráter heterogêneo da diversidade 
de sua demanda educacional, o que, por sua vez, pressupõe o desafio da reconfiguração do espaço escolar, não apenas em relação à sua estrutura física e material, mas também no que diz respeito aos aspectos atitudinal e metodológico, com vistas a atender a heterogeneidade desse alunado (MANTOAN, 2015).

As Diretrizes Curriculares Nacionais para a Educação Infantil (BRASIL, 2010, p. 18) determinam, inclusive, que as propostas pedagógicas, para esta etapa da Educação Básica, têm como objetivo

[...] garantir à criança acesso a processos de apropriação, renovação e articulação de conhecimentos e aprendizagens de diferentes linguagens, assim como o direito à proteção, à saúde, à liberdade, à confiança, ao respeito, à dignidade, à brincadeira, à convivência e à interação com outras crianças (BRASIL, 2010, p. 18).

Consideramos, entretanto, que a reconfiguração da Educação Infantil, na perspectiva da educação inclusiva, decorrente das recomendações da PNEEPEI, e o objetivo expresso nessas diretrizes curriculares só farão sentido se as crianças, no que diz respeito principalmente aos aspectos atitudinais e metodológicos, forem privilegiadas como seres ativos, criativos e produtores de cultura, que contribuem para o avanço do conhecimento (CORSARO, 2011).

Dessa perspectiva, partimos da premissa, no presente artigo, que, do ponto de vista da pesquisa, é preciso privilegiar suas experiências, escutando-as e considerando-as como protagonistas. As crianças são atores sociais que interagem com o meio social e se desenvolvem num espaço e tempo compartilhados com outras pessoas. Portanto, dar voz às crianças, não só nas pesquisas, mas também nas práticas pedagógicas, é estratégia fundamental para que se tornem participantes efetivas do processo educativo.

A esse respeito, Demartini (2002) menciona que as crianças devem ser reconhecidas como grupos sociais que possuem suas características, vivências, culturas específicas e devem ser escutadas, uma vez que fazem parte de uma sociedade onde influenciam e são influenciadas. Isso requer o distanciamento de concepções que não consideram a realidade social na qual estão inseridas, bem como a necessidade de investimentos em práticas pedagógicas colaborativas que favoreçam a aproximação e envolvimento delas e dos educadores em processos investigativos.

O conhecimento da realidade das crianças e da escola, bem como a ampliação do universo de conhecimentos construídos, colaborativamente, entre professores e alunos, constituem, portanto, um profícuo contexto para o trabalho com a temática ora proposta, ou 
seja, a atuação com a diversidade na Educação Infantil, numa perspectiva inclusiva, que pode ocorrer a partir da alfabetização científica.

A alfabetização científica se relaciona com a apropriação dos conhecimentos científicos à vida social das pessoas, possibilitando que um indivíduo, ainda que em diferentes níveis, pense de forma científica e racional sobre sua realidade. Embora venha sendo considerada pertinente ao trabalho pedagógico realizado a partir das séries iniciais do ensino fundamental (LORENZETI; DELIZOICOV, 2001) e considerando a antecipação do ensino de conteúdos de leitura e escrita para crianças que frequentam uma turma de Infantil II, acreditamos ser essencial que seja iniciada a partir da Educação Infantil, tendo em vista ser essa a primeira etapa da Educação Básica, uma vez que é nessa etapa que muitos conceitos começam a ser construídos e/ou sistematizados, em momentos de rica aprendizagem.

Frente às considerações apresentadas, o presente artigo objetivou investigar as concepções sobre diversidade junto às crianças de uma classe de Educação Infantil II, familiares e professora, a partir do projeto "Simplesmente Diferente", elaborado e desenvolvido colaborativamente pelos mesmos.

\section{Percurso metodológico}

O percurso metodológico foi empreendido sob uma perspectiva colaborativa, considerando a alfabetização científica como possibilidade para a atuação pedagógica na Educação Infantil, conforme mencionado anteriormente, e a heterogeneidade característica da diversidade de alunos da Educação Infantil, por meio da metodologia de projetos, com uma classe de Educação Infantil II, com faixa etária entre cinco e seis anos, durante um semestre, em uma escola particular, de um município de médio porte do interior paulista, sob anuência do Comitê de ética de uma universidade estadual, registrada no protocolo $\mathrm{n}^{\circ}$. 19052. A seguir, caracterizamos, brevemente, a metodologia de projetos sob a compreensão aqui adotada.

\section{Projeto de trabalho: uma alternativa metodológica de pesquisa com crianças no processo de geração de dados}

Os projetos de trabalho se configuram numa alternativa metodológica importante, pois coloca a criança no centro do processo investigativo, bem como favorece o desenvolvimento de diferentes habilidades, da imaginação e do pensamento crítico, a partir da realidade vivenciada. Como os temas do projeto nascem a partir dos interesses das crianças, ampliando 
seus conhecimentos sobre assuntos de interesse coletivo, cabe ao professor assumir papel de mediador no processo de apropriação desses conhecimentos, proporcionando-lhes, em colaboração, atividades significativas que consideram a criança como ser histórico, social e cultural e promovam a participação ativa do aluno na resolução de problemas do cotidiano mediante conhecimento científico.

É importante que, desde a Educação Infantil, as crianças tenham atividades que fomentem a investigação, pois a infância é marcada pela curiosidade, a criança busca, a todo o momento, o conhecimento do mundo e, se o professor souber aproveitar a curiosidade natural das crianças, a investigação poderá ser o melhor caminho para lhes proporcionar as respostas que precisam (KATZ, 2005).

Há diferentes caminhos para o desenvolvimento dessa investigação. Cada assunto apresenta problemáticas diferentes e pode levar a encaminhamentos diversos. Não há como prever, a priori, a definição de um projeto, pois o tema deve emergir do interesse das crianças e deve ser significativo para todos. Quando surgem muitos temas, então o procedimento tem que ser democrático e requer a votação. Entretanto, para a organização, sistematização e execução do projeto, a participação, o diálogo e as pesquisas sobre o tema definido devem ser constantes, pois,

Os projetos de trabalho são uma das estratégias que busca o ensino transdisciplinar, pois constituem-se de problemas ou fontes geradoras de problemas. O trabalho por meio de projetos cria no aprendiz novas necessidades de conhecimento, interesse e envolvimento no objeto de estudo. (HELM et al., 2005, p. 21).

Embora não haja uma sequência única a ser seguida, pois o professor tem autonomia para conduzir com as crianças o processo de investigação, Katz (2005, p. 29) propõe três momentos para o desenvolvimento de um projeto de trabalho, que compreendem:

1 Esclarecimento dos objetivos a serem alcançados e as questões que serão respondidas. Trata-se também do compartilhamento que as crianças farão sobre o seu conhecimento prévio sobre o assunto, possibilitando ao professor registrar o ponto de partida e os conhecimentos que precisarão ser desconstruídos ou reelaborados. É apresentação da proposta;

2 Coleta de dados feita pelas próprias crianças. É o momento que vai permitir que a criança se aproprie do conhecimento social do tema do projeto, quer seja através de um trabalho de campo, ou de uma entrevista que possam fazer a uma pessoa que conhece bem o tema e o registro dessas informações. Ao fazer a coleta de dados, as crianças desenvolvem sua autonomia em busca de conhecimento, percebendo que o conhecimento escolar tem sentido e significado na sociedade. 
3 Acontece "a atividade de culminância, em que a história da investigação e suas descobertas são compartilhadas". Trata-se da apresentação do conhecimento construído ao longo do projeto, as respostas e objetivos que foram alcançados.

Assim, consideramos esses três momentos no processo de geração de dados, que nos permitiu a definição e delineamento do projeto "Simplesmente Diferente", aqui brevemente explicitado.

\section{Projeto "Simplesmente Diferente": encontro com a diversidade}

O projeto "Simplesmente Diferente" emergiu, portanto, dessa metodologia de projetos de trabalho, contemplando três momentos que permitiram a consecução do objetivo proposto: - primeiro momento, que envolveu a discussão coletiva acerca dos temas de interesse das crianças, mediado pela professora, denominado de reflexão colaborativa, no qual sobressaiu, após votação, o tema diversidade, uma vez que as crianças elencaram as diferentes características que apresentavam e que as distinguiam entre si, por ocasião do contato com um aluno cadeirante, na escola, e a partir da leitura de um livro de Tatiana Belinki (1999), intitulado "Diversidade".

Após a definição do tema, o projeto recebeu várias propostas de títulos, mas a escolha foi alcançada mediante votação da turma. Para tal, foi construída uma urna para votação e cédulas com as fotos das propostas de títulos. A votação foi secreta e realizada em data marcada para que todos os alunos pudessem estar presentes. Posteriormente à computação dos votos, coletivamente, o título do projeto foi alcançado: "Simplesmente diferente".

Com vistas aos esclarecimentos acerca dos objetivos a serem alcançados e das questões a serem respondidas por meio do projeto, conforme proposto por Katz (2005), dois questionamentos foram importantes para o delineamento do processo investigativo: o que já sabemos sobre o tema diversidade? E o que queremos saber?

A partir da primeira questão, as hipóteses levantadas pelas crianças e consideradas no processo metodológico compreenderam: “[...] existem diferentes deficiências [...]”; “[...] existem pessoas que não enxergam, não escutam e não falam”; "[...] crianças com deficiências sofrem bullying”; e "[...] algumas precisam de cadeira de roda e outras usam óculos". A segunda questão, por sua vez, visou responder o que segue aqui exemplificado, a partir de excertos de falas das crianças: "[...] o que é diversidade?”; "[...] como se vive com 
a diversidade?"; "[...] é difícil andar de cadeiras de rodas”; "[...] por que a criança tem olhos puxados?”; e "[...] será que as crianças com deficiência brincam?”.

A partir dessas hipóteses e questionamentos, o projeto de trabalho "Simplesmente Diferente" foi direcionado aos seguintes aspectos: fomento à construção de valores; desenvolvimento da autoestima, com vistas às relações entre as crianças; desenvolvimento da imagem de si visando à atuação das crianças de forma mais independente; favorecimento da integração entre escola e família; e o trabalho direcionado às regras sociais de convivência com o outro. Posteriormente à definição do tema e título do projeto, objetivo e questionamentos a serem respondidos, nos reportamos às recomendações expressas por Katz (2005) quanto à coleta de dados feita pelas próprias crianças, por meio de três encontros dialogados entre as crianças, seus familiares e a professora.

Por meio da leitura do livro "Diversidade" e de informações retiradas de diferentes fontes que foram pesquisados pelas crianças na própria escola e também em casa com os pais, foram realizados os encontros dialogados, primeiramente entre as crianças e professora e em seguida com a família. Nesse momento, as crianças foram capazes de realizar a articulação entre os estudos científicos apreendidos e a exploração do mundo que estão inseridos, a partir da construção da temática da diversidade.

No processo de estruturação do tema houve a preocupação com a construção de ações que favorecessem a vivência das crianças com o tema da diversidade. Nesse processo foram desenvolvidas várias práticas, tais como: jogos protagonizados; brincadeiras diversas; modelagens; desenhos infantis; e palestras com especialistas. No entanto, para fins de discussão neste artigo selecionamos apenas uma: a confecção de bonecos. Os bonecos foram confeccionados com o intuito de proporcionar às crianças momentos de brincadeiras, de modo que esses bonecos participassem do projeto com as crianças e ilustrassem a questão da diversidade.

A construção desses bonecos envolveu a participação da família. Os pais receberam um convite para participarem de um encontro dialogado com as crianças e a professora, com o intuito de explicitar os objetivos do projeto e fazer a apresentação da proposta da confecção de bonecos. Durante uma manhã, num fim de semana, as famílias foram até a escola para a confecção dos bonecos. Foi solicitado a elas que levassem retalhos e materiais de costura. Cada família recebeu um kit com informações a respeito das características e/ou condições anteriormente aventadas pelas crianças e, em equipes, montaram os bonecos. Cada criança tinha o seu boneco específico e junto desse boneco havia um caderno de registro. 
Semanalmente as crianças levavam o boneco para casa e o caderno para fazerem o registro das atividades vivenciadas com o boneco. Essas vivências das crianças eram representadas por meio de desenhos, fotos e pela escrita. Os pais auxiliavam na escrita das crianças. A cada final de semana, a criança levava um boneco diferente e o procedimento de registro era o mesmo.

Como fundamento da proposta que foi apresentada com a confecção de bonecos, frente às diferentes atividades que foram desenvolvidas considerando a organização dos espaços de aprendizagem, a confecção de materiais e tempos, cabe destacar que as Diretrizes Curriculares Nacionais para a Educação Infantil preconizam, em relação às propostas pedagógicas e a organização de espaços, tempos e materiais, que deve ser garantida “[...] a acessibilidade de espaços, materiais, objetos, brinquedos e instruções para as crianças com deficiência, transtornos globais de desenvolvimento e altas habilidades/ superdotação" (BRASIL, 2010, p. 20).

Nesse sentido é fundamental que as crianças possam experimentar os limites e possibilidades dos espaços da escola, do ponto de vista de crianças com deficiência, e aprendam que, apesar das dificuldades, os ambientes e materiais precisam ser configurados de modo que atendam as diversidades.

Por fim, na "[...] atividade de culminância”, Katz (2005) propõe, para esse momento, o compartilhamento das descobertas, o alcance de respostas e dos objetivos propostos. Esse momento foi contemplado por meio da observação participante realizada pela professora, que culminou na descrição minuciosa de todo o processo investigativo com o intuito de acolher a riqueza das vivências com e das crianças e como essas vivências foram compreendidas pelos seus próprios atores: as crianças (CORSARO, 2009).

A observação participante favoreceu o contato com a criança, permitindo conhecer melhor o seu modo de pensar, sentir e agir sobre as questões relacionadas à questão da diversidade. Todas as etapas do processo foram registradas mediante portfólios confeccionados pelas próprias crianças, considerando suas elaborações de escrita, as fotografias da professora e os desenhos infantis. Por meio das fotografias se "[...] constrói o próprio olhar do pesquisador, apresentando-se como outras possibilidades de escritas - outros textos - da realidade estudada" (FILHO; BARBOSA, 2010, p.21).

Os desenhos infantis trouxeram importantes contribuições ao projeto, sempre retratando a "produção cultural" das crianças e servindo como um instrumento revelador das representações infantis (FILHO; BARBOSA, 2010), o que possibilita conhecer o mundo por 
meio do olhar da criança apresentando aquilo que tem significado e sentido para ela (FERREIRA, 1996).

Barbosa e Horn (2008, p. 33) ressaltam a importância da avaliação e da comunicação nesse processo, ao destacarem a relevância do registro e documentação da aprendizagem de todos os envolvidos, o que se constituirá na "memória pedagógica do trabalho".

A partir do percurso metodológico empreendido, a análise compreendeu eixos que emergiram dos dados gerados, sendo aqui considerado, para fins de discussão, o eixo "Concepções sobre diversidade no contexto da Educação Infantil na perspectiva inclusiva", que contemplou a compreensão docente, das crianças e dos familiares envolvidos no projeto acerca dessa temática e sua relação com a Educação Infantil na perspectiva da educação inclusiva.

\section{Resultados e discussão}

A apresentação dos resultados foi aqui organizada, conforme destacado anteriormente, considerando o eixo de análise "Concepções sobre diversidade no contexto da Educação Infantil na perspectiva inclusiva", sendo tal discussão realizada com base nos excertos dos enunciados da professora, das crianças e de seus familiares, conforme segue.

\section{Concepções sobre diversidade no contexto da Educação Infantil na perspectiva inclusiva}

A professora da turma, sobre o modo como compreende a temática diversidade, esclareceu:

O que seria essa diversidade? É mostrar o quanto as pessoas se diferem uma das outras, por vários aspectos, porque a educação, nós que estamos à frente da educação com as nossas crianças... uso até uma frase de Jhon Dewey que dizia... "[...] a educação não é uma preparação para a vida, ela é a própria vida!", então não dá para preparar as crianças hoje para que elas atuem como cidadãs conscientes do seu papel de acolhimento, de respeito, com uma visão sem preconceito para com o próximo somente quando ela estiver fora da escola, quando ela se tornar um adulto, mas já é para agora, a educação já é aquilo que a criança está vivenciando. [...] Então eu conceituaria a diversidade como algo muito abrangente, complexo, de responsabilidade da escola sim, também, de mostrar para essa criança que cada pessoa tem o seu papel, que cada pessoa tem o seu jeito de ser e que nós temos de respeitar, acima de tudo. 
É possível observar que a professora pareceu demonstrar a compreensão que diversidade não é uma temática que diz respeito apenas aos alunos público-alvo da Educação Especial, assim como abrange a questão das diferenças, sendo possível inferir que a deficiência é então aqui concebida como mais singularidade, dentre as apresentadas pelos alunos, de modo geral. Cabe ressaltar, também, que essa compreensão da professora indicou o alinhamento com o paradigma de inclusão, que prevê o reconhecimento e enfrentamento das singularidades da diversidade característica do público escolar.

Conforme apontado por Silva (2006), “[...] é o grupo que coletivamente conceitua uma diferença, que lhe dá importância e valor", sendo a diferença “[...] socialmente formulada, na razão particular da existência dos grupos sociais que são definidos pelos tipos de interação e intensidade dos conflitos".

Dessa perspectiva, foi possível depreender, da fala da professora, que sua compreensão sobre diversidade se articula com seu entendimento acerca do papel do professor da Educação Infantil, no que diz respeito a essa temática, ao reconhecer que “[...] ensinar a diversidade para a criança é um compromisso também da escola. Então nossa intenção era principalmente ir tirando essa visão preconceituosa da falta de capacidade do outro, a partir da deficiência que ele apresentava, a partir da diversidade que ele apresentava".

A professora pareceu refutar aqui a condição de deficiência concebida a partir do lugar da falta, da incapacidade. O que, em si, pode remeter a um olhar sob o qual a diversidade foi compreendida como constitutiva das relações sociais, a deficiência como diferença, e esta, consequentemente, como constitutiva do humano. Isso pareceu refutar, então, a visão reducionista que concebe diversidade como um conjunto de traços identitários, desatrelada da existência humana e da alteridade constituída em tais relações; deficiência como doença e diferença como traço identitário atrelado a características individuais (GIROTO; NASCIMENTO, 2016; MARQUES; GIROTO, 2016).

Ao esclarecer sobre sua compreensão acerca da temática diversidade, a professora também se reportou a aspectos da formação docente, ao reconhecer que os professores, de modo geral, e os da Educação Infantil, especificamente, ainda não se encontram preparados para a atuação com a diversidade de alunos na perspectiva da educação inclusiva, ao mesmo tempo em que chama a atenção para a necessidade de investimentos tanto nas formas de organização escolar quanto na formação docente, que permita não apenas compreender tal temática, mas efetivamente atuar nessa perspectiva inclusiva. 
Não estamos preparados para atuar com a diversidade de alunos não, mas nós temos que nos reiniciar, essa é a palavra. Mário Sérgio Cortella dizia em uma entrevista que nós devemos usar como exemplo, as nossas tecnologias, nosso GPS, que quando erram a rota, se reiniciam, recalculam a rota. E eu vejo que nós, professores, hoje estamos recalculando a rota, eu falo isso para você e fico até emocionada, porque a gente precisa recalcular a rota todo tempo. Mesmo sendo um professor que nunca, nunca recebeu em sala de aula uma criança com alguma deficiência, uma hora ela se apresenta, uma hora ela chega, e ela chegando para nós, não tem o não, não tem esse não sei, eu não vou cuidar, eu não vou zelar, eu não vou ensinar ou eu não vou compartilhar. O que tem, na verdade, é um reiniciar e recalcular a rota, procurar saber, estudar, ler para melhor atender essa criança, mas dizer que os professores estão preparados, não.

Ao mencionar a falta de preparo para atuação com a diversidade de alunos, a professora destacou isso como uma lacuna em sua formação inicial, ao dizer que "[...] o que nós tínhamos, na formação inicial, era aquilo que nós buscávamos, aprendíamos por meio da literatura, a gente ia lendo e ia buscando algumas bibliografias e tentando compreender como nós poderíamos abordar com as crianças o assunto". Reconheceu, "[...] respondendo por mim, formação para isso não tive não".

Glat e Pletch (2010) chamam atenção para o distanciamento entre as propostas de formação inicial e a realidade vivida pelo professor, no que diz respeito à inclusão da diversidade do público escolar, fato corroborado pela professora quando acrescenta que,

Na realidade que eu vivo, cada vez mais nós temos recebido crianças com necessidades especiais e a gente tem buscado, eu vejo por mim e por minhas amigas, tanto nas leituras, como na nossa prática diária, como nas pessoas que fazem parte da nossa equipe, esse embasamento teórico para que a gente possa saber como lidar na prática, mas estamos reiniciando todos os dias. Porque tivemos muito pouco na nossa formação. (A)

Os excertos anteriormente apresentados parecem indiciar que a professora tem consciência de que tanto a escola quanto o professor têm importante e fundamental papel nos modos de constituição e apropriação de conhecimentos sobre o tema diversidade, com seus alunos da Educação Infantil, o que também perpassa pela atitude favorável em relação à inclusão de todos os alunos (GLAT; PLETSCH, 2010). Entretanto, é importante ressaltar que, sendo a diferença constitutiva do humano e a diversidade forjada nas relações sociais, o aprofundamento dessa discussão, na escola e entre os professores, precisa alcançar essa compreensão (MARQUES; GIROTO, 2016). 
Assim como mencionou a formação inicial como justificativa para as dificuldades em abordar esse tema com seus alunos da Educação Infantil, apontou a formação continuada como resposta a essa lacuna, ao informar que, com o tema proposto,

Hoje eu tenho buscado uma formação por meio de uma pós-graduação para poder entender um pouco mais como lidar, como atendê-los em sala de aula com questões sistematizadas mesmo, com respeito para com o ritmo de cada um, com aquilo que eu posso oferecer [...] contribuindo para que a criança aprenda dentro desse espaço escolar. Que possam compartilhar vivências, experiências.

Assim como apontou que,

[...] o colégio abraça nossas ideias, abraça tudo aquilo que vem de nós, [...] isso daí dentro daquilo que é possível a escola fazer, enquanto coordenação, direção e tudo mais, sim, mas a preparação a grosso modo, dizendo, a preparação maior, ela veio de nós mesmas, das professoras, de conseguir escrever aquilo que precisava, botar no papel a ideia, de ir em busca de materiais que pudessem auxiliar nesse dia, buscar pessoas que pudessem nos ajudar dentro e ora da escola. Então é isso, o professor faz a parte dele, busca tudo, organiza e a escola vem dando esse respaldo que é possível diante dessa organização. (A)

Esses excertos explicitam contradições expressas pela professora, pois ainda que tenha compreendido diversidade como própria do humano e constituída nas/por relações sociais, pareceu não contemplar a responsabilização das políticas públicas educacionais e da própria escola acerca da necessidade de essa temática figurar, sistematicamente, no currículo da Educação Infantil, o que requer sua inserção também nas propostas de formação inicial.

No que diz respeito às crianças, durante o percurso do projeto "Simplesmente Diferente", foram percebendo que as pessoas possuem condições diversas. Compreenderam, por exemplo, que convivem com pessoas com deficiências no cotidiano, não apenas na escola, e expressaram isso em suas falas, situação aqui exemplificada pelo excerto: “[...] eu aprendi que a diversidade existe de várias formas, não está só nas pessoas diferentes de mim, porque não tem perna, braço. Somos diferentes, mas isso é bom, porque podemos conviver e aprender com todos" (EP).

Demartini (2002) ressalta que a criança expressa suas fantasias, suas construções próprias, que podem ser contadas de diferentes formas, a exemplo do que uma criança revelou no excerto: "O mundo não está preparado para essas pessoas, eles sofrem bullying” (F), ao se referir ao cotidiano de pessoas consideradas diferentes daquelas tomadas como "normais" e à sua compreensão sobre como a sociedade lida com essas pessoas. 
Ao debaterem sobre a vida e a rotina de pessoas com deficiências, as crianças puderam perceber que, embora essas pessoas tenham características que as diferem das demais, entretanto, puderam perceber que todos, em geral, possuem características que os distinguem e os tornam únicos, o que não inviabiliza a convivência em sociedade, o que pode ser aqui retratado pelo excerto: “[...] Não é porque tem deficiência que uma pessoa não pode estudar, trabalhar, se divertir, conviver com os demais" (AL). Bem como demonstraram ter consciência de que a sociedade tem responsabilidade na inclusão da diversidade em todas as esferas da atividade humana, ao expressarem: "[...] mas não depende só da pessoa. Ela precisa encontrar condições para trabalhar e estudar, tendo ou não deficiência” (HC).

Essa articulação entre os estudos científicos e a exploração do mundo que faz parte do entorno da criança favorecem o desenvolvimento das suas mais variadas habilidades, levandoas a compreensões que somente seriam possíveis mais tarde, em fase adulta (MORAES, 2015).

A questão da diversidade fomentou o interesse e curiosidade não apenas das crianças, mas também de suas famílias, perspectivados em compreender e ampliar os conhecimentos em torno da temática. No entanto, cabe ressaltar que o tema diversidade foi apresentado por um dos familiares como

[...] uma perspectiva que deve ser fomentada pela escola, com o intuito de mostrar o diferente, a escola mostra o quanto não somos iguais e que mesmo tendo essa diferença, os alunos também não são iguais. Então o que difere? Por que difere? (MS)

Fica evidente, no relato acima, que esse familiar entende que é papel da escola trabalhar com conceitos como diversidade, uma vez que nem sempre as famílias possuem a apropriação desse conhecimento que faz parte da vida social. Daí a importância de se fomentar a interação com as famílias e comunidade no entorno da escola, por meio, por exemplo, da Alfabetização Científica desde a Educação Infantil, possibilitando ao indivíduo, ainda que em diferente faixa etária, condições de pensar de forma científica e racional a realidade que vive (LORENZETTI; DELIZOICOV, 2001).

As impressões dos pais e também das crianças ficaram evidentes na confecção dos bonecos, pois logo de início era visível o medo e o receio das crianças em relação às pessoas com deficiências, principalmente com cadeirantes e deficientes visuais, pessoas com as quais haviam tido contato na própria escola. 
[...] eи lembro que meu filho tinha medo da cadeira de rodas, de pessoas deficientes visuais, era como se ele colocasse as mãos numa pessoa como essa e fosse uma doença contagiosa. A princípio não queria nem participar do projeto e depois foi se acostumando, o assunto se tornou mais diário, mais do conhecimento dele e aí ele começou a perceber que essas situações faziam parte do dia-a-dia de muita gente, fazia parte do dia-a-dia de muitas pessoas. $(M)$

Destacamos que a avaliação em todo esse processo foi fundamental. Assim como Barbosa e Horn (2008, p. 97), acreditamos na especificidade da avaliação na Educação Infantil e reconhecemos que observar, refletir, documentar e analisar o processo de constituição da criança enquanto ser histórico, social e cultural são dimensões que precisam ser consideradas e os projetos de trabalho podem servir de potencial para se alcançar esse sujeito social.

\section{Considerações finais}

Por meio dos projetos de trabalho foi possível compreender o caráter heterogêneo da diversidade e também a necessidade de uma reconfiguração não apenas do espaço escolar, mas de toda uma cultura social, no contexto da Educação Infantil, acerca da temática abordada nesse estudo e tratada por meio do projeto "Simplesmente Diferente", que contemplou os momentos de trabalho que permitiram a consecução do objetivo proposto: esclarecimento dos objetivos a serem alcançados e as questões que serão respondidas; coleta de dados realizada pelas próprias crianças; e a atividade de culminância.

Ademais, os encontros dialogados e as reflexões colaborativas favoreceram a organização conjunta com as crianças, familiares e professora das atividades desenvolvidas durante o projeto, bem como a articulação de conhecimentos específicos, a exemplo da área da Educação Especial.

A investigação aguçou a curiosidade sobre a diversidade não só dos pequenos, mas também de todos os envolvidos, professora e famílias, possibilitando o desenvolvimento da Alfabetização Científica de/com todos.

As atividades desenvolvidas junto ao projeto privilegiaram uma postura investigativa, a cultura, as falas e ações das crianças, colocando-as no centro da pesquisa. Com base nessa proposta, destacamos nesse artigo a prática da confecção dos bonecos, uma vez que por meio deles, dos encontros dialogados e das reflexões colaborativas documentadas, foi perceptível a mudança de concepções das crianças em relação à diversidade, compreendendo a necessidade 
de garantir a esse público específico o respeito às suas diferenças e a garantia de um ensino que atenda suas especificidades.

A apresentação dos resultados foi organizada considerando o eixo de análise "Concepções sobre diversidade no contexto da Educação Infantil na perspectiva inclusiva", obviamente apenas um breve recorte da situação investigada, mas que possibilitou a reflexão sobre o tema em questão.

Destacamos, dentre as possíveis conclusões, o fato de que, ainda que a professora tivesse consciência de seu papel na constituição e apropriação de conhecimentos sobre o tema diversidade, permanece fixada a ideia de que mudanças atitudinais por parte do professor serão suficientes para a sistematização do trabalho pedagógico voltado à diversidade. Ressaltamos, também, a importância de se fomentar o desenvolvimento da Alfabetização Científica desde a Educação Infantil, de modo que o sujeito tenha condições de pensar de forma científica e racional a realidade em que está inserido, bem como a necessidade de o tema diversidade, sob a compreensão de sua constituição nas relações sociais e atreladas às condições de existência humana, figurar, mais assertivamente, nas políticas educacionais e currículo da Educação Infantil.

\section{REFERÊNCIAS}

BARBOSA, M. S.; HORN, M. G. S. Projetos pedagógicos na educação infantil. Porto Alegre: Artmed, 2008.

BELINKI, T. Diversidade. São Paulo: FTD, 1999.

BRASIL. Política Nacional de Educação Especial na Perspectiva da Educação Inclusiva. Brasília, Brasil.2008.

BRASIL. Ministério da Educação. Secretaria de Educação Básica. Diretrizes Curriculares Nacionais para a Educação Infantil. Brasília: MEC, SEB, 2010.

CORSARO, W. A. Métodos etnográficos no estudo da cultura de pares e das transições iniciais na vida das crianças. In: MÜLLER, F.; CARVALHO, A. M. A. (Org.). Teoria e prática na pesquisa com crianças: diálogos com William Corsaro. São Paulo: Cortez, 2009. p. 83-103.

CORSARO, W. A. Sociologia da infância. São Paulo: Artmed, 2011.

DEMARTINI, Z. B. F. Infância, pesquisa e relatos orais. In: PRADO, P. D.; DEMARTINI, Z. B. F.; FARIA, A. L. G. (Org.). Por uma cultura da infância: metodologias de pesquisa com crianças. Campinas: Autores Associados, 2002. p. 01-17. 
FERREIRA, G. de M. (Org.). Palavra de professor (a): tateios e reflexões na prática da Pedagogia Freinet. Campinas (SP.): Mercado de Letras, 2003. p. 49-53.

FILHO, A. J. M. BARBOSA, M. C. S. Metodologias de pesquisa com crianças. Capes, s.i, p. 08-28, 2010.

GIROTO, C. R. M.; NASCIMENTO, B. A. B. Inclusão e Educação Infantil no Brasil. Journal of Research in Special Educational Needs, v. 16, p. 608-613, 2016.

GIROTO, C. R. M.; MARQUES, J. B. Trabalho docente com alunos público-alvo da Educação Especial na Educação Infantil. Revista Ibero-Americana de Estudos em Educação, v. 11, p. 895-910, 2016.

HELM, J. H. et al. O poder dos projetos: novas estratégias e soluções para a educação infantil. Porto Alegre: Artmed, 2005. 176p.

KATZ, L. G. A construção de sólidos fundamentos para as crianças. In: HELM, J. H.; BENEKE, S. O Poder dos projetos: novas estratégias e soluções para a educação infantil. Porto Alegre: Artmed, 2005.

LORENZETTI, L.; DELIZOICOV, D. Alfabetização Científica no Contexto das Séries Iniciais. Ensaio. Pesquisa em Educação em Ciências, Belo Horizonte, v. 03, n. 3, p. 37-50, 2001.

MANTOAN, M.T. E. Educação Especial na Perspectiva Inclusiva: o Que Dizem os Professores, Dirigentes e Pais. Revista Diálogos e Perspectivas em Educação Especial, v. 2, n. 1, p. 23-42.

MORAES, T. S. V. O desenvolvimento de processos de investigação científica para o 10. ano do ensino fundamental. $248 \mathrm{f}$. Tese (Doutorado em Educação) - Faculdade de Educação. Universidade de São Paulo/USP, São Paulo, 2015. Disponível em: http://www.teses.usp.br/teses/disponiveis/48/48134/tde-15062015-142924/en.php. Acesso em: 12 fev. de 2016.

SILVA, L. M. A deficiência como expressão da diferença. Educação em Revista, Belo Horizonte. v. 44, p. 111-133, 2006.

\section{Como referenciar este artigo}

ARAUJO, Luciana Aparecida de.; CORDEIRO, Ana Paula.; GIROTO, Claudia Regina Mosca. Um encontro com a diversidade na Educação Infantil por meio do projeto "Simplesmente Diferente" sob a perspectiva do professor, da criança e da família. Revista Ibero-Americana de Estudos em Educação, Araraquara, v. 14, n. esp. 1, p. 775-790, abr., 2019. E-ISSN: 1982-5587. DOI: 10.21723/riaee.v14iesp.1.12206

Submetido em: 06/08/2018

Aprovado em: 21/09/2018 